\title{
Cancer in pregnancy: a 15-year descriptive analysis of 86 consecutive patients
}

\author{
E. Di Loreto ${ }^{1}$, C. Castellani ${ }^{1}$, B. Buonomo², G. Polverino ${ }^{1}$, E. Grossi ${ }^{1}$, L. Buggio ${ }^{1}$, M.W. Ossola1 ${ }^{1}$, S. Passera \\ ${ }^{1}$, F. M. Cribiù ${ }^{1}$, C. Blundo ${ }^{1}$, F. Peccatori ${ }^{2}$, G. Scarfone ${ }^{1}$ \\ 1. Fondazione IRCCS Ca' Granda Ospedale Maggiore Policlinico Milano, Milan, Italy \\ 2. Istituto Europeo Di Oncologia, Milan, Italy \\ E-mail: eugenia.diloreto@unimi.it
}

\section{INTRODUCTION}

The maternal diagnosis of cancer complicates approximately $0,1 \%$ of all pregnancies. The most frequently diagnosed malignancies are breast cancer, cervical cancer, lymphoma, ovarian cancer and melanoma. Although chemotherapy can be administered during pregnancy, its effects on obstetric and neonatal outcome are still largely unknown. The aim of this study is to describe the oncologic management as well as the obstetric and perinatal outcomes in a consecutive series of patients with cancer during pregnancy

\section{METHODS}

We provided descriptive oncologic, obstetric and neonatal data from a cohort of pregnant patients diagnosed with primary invasive cancer between August 2004 and August 2019, retrospectively collected from clinical databases of IRCCS Policlinico di Milano and Istituto Europeo Di Oncologia (Milan, Italy).

\section{DISCUSSION}

We observed 86 consecutive patients with a diagnosis of malignancy during pregnancy: breast cancer was the most common type $(74,4 \%)$, followed by lymphomas $(10,4 \%)$. Patients with ongoing or missing oncological, obstetrical or neonatal data were excluded. Of the 62 eligible patients, $14 \%$ received surgical treatment, $32 \%$ chemotherapy and $50 \%$ a combination of both. For almost all pregnancies, timing of delivery was previously planned: $38 \%$ with labour inductions and $54 \%$ with elective caesarean sections, at a mean gestational age of 36 weeks. All pregnancies ended in a livebirth. Half of deliveries were preterm, mainly iatrogenic due to obstetric or oncologic indications: $3.2 \%$ were very low preterm, $6,4 \%$ moderate preterm and $45 \%$ late preterm.

The frequency of small for gestational age (birthweight $<10^{\circ}$ percentile) was $14,5 \%$ : in 8 out of 9 cases, mothers were treated with chemotherapy during pregnancy.

\section{CONCLUSIONS}

This study confirms a higher overall frequency of premature birth and a higher rate of small for gestational age compared with general population. In order to have a better assessment of the toxicity of chemotherapy during pregnancy, we are currently investigating its foetal sequelae through histologic analysis of placental tissue and paediatric follow-up.

\begin{tabular}{|rl|}
\hline \multicolumn{2}{|c|}{ Cancer types in pregnancy $(\mathrm{N}=86)$} \\
\hline Breast cancer & $64(74,4 \%)$ \\
\hline Lymphoma & $9(10,4 \%)$ \\
\hline Lung cancer & $3(3,4 \%)$ \\
\hline Cervical cancer & $2(2,3 \%)$ \\
\hline Ovarian cancer & $2(2,3 \%)$ \\
\hline Thyroid cancer & $2(2,3 \%)$ \\
\hline Others & $4(4,6 \%)$ \\
\hline &
\end{tabular}

\begin{tabular}{|c|c|}
\hline \multicolumn{2}{|c|}{ Patients characteristics } \\
\hline Age at diagnosis & Mean 35 years (Range $25-43$ ) \\
\hline Gestational age at diagnosis & Mean 17 weeks (Range 3-37) \\
\hline \multicolumn{2}{|c|}{ Treatment in pregnancy } \\
\hline Chemotherapy & 20/62 patients \\
\hline Surgery & $9 / 62$ patients \\
\hline Chemotherapy and Surgery & $31 / 62$ patients \\
\hline No treatment & $2 / 62$ patients \\
\hline
\end{tabular}

\begin{tabular}{|rl|}
\hline \multicolumn{2}{|c|}{ Obstetrical Outcomes } \\
\hline Gestational age at delivery & Mean 36 weeks (Range $27-40$ ) \\
\hline$<34$ weeks & $5 / 62$ \\
\hline $34-37$ weeks & $28 / 62$ \\
\hline$>37$ weeks & $27 / 62$ \\
\hline Missing data & $2 / 62$ \\
\hline Mode of delivery \\
\hline Vaginal birth & $17 / 62$ \\
\hline Caesarean section & $43 / 62$ \\
\hline Missing data & $2 / 62$ \\
\hline Birth weight \\
\hline$<5^{\circ}$ percentile & $4 / 62$ \\
\hline $5^{\circ}-10^{\circ}$ percentile & $5 / 62$ \\
\hline $10^{\circ}-50^{\circ}$ percentile & $29 / 62$ \\
\hline $50^{\circ}-90^{\circ}$ percentile & $16 / 62$ \\
\hline$>90^{\circ}$ percentile & $2 / 62$ \\
\hline Missing data & $6 / 62$ \\
\hline
\end{tabular}

Disclosure: The authors declare that they have no conflicts of interest. 